\title{
Administration of thymoquinone offer a protective effect through the apoptogenic and antioxidant pathway in acute liver failure induced by taxol
}

\author{
Shiva Roshankhah', Cyrus Jalili², Amir Farmandeh', Mohammad Reza Salahshoor
}

\author{
'Department of Anatomical Sciences, Medical School, Kermanshah University of Medical Sciences, Kermanshah, Iran. \\ ${ }^{2}$ Medical Biology Research Center, Kermanshah University of Medical Sciences, Kermanshah, Iran. \\ Corresponding Author: Mohammad Reza Salahshoor (E-Mail: reza.salahshoor@yahoo.com) \\ (Submitted: 15 January 2020 - Revised version received: 02 February 2020 - Accepted: 09 February 2020 - Published online: 26 April 2020)
}

\begin{abstract}
Objectives Due to the increasing use of chemotherapy drugs and herbs in medicine, this study was designed to assess the effects of thymoquinone and taxol on apoptogenic, oxidative, and histomorphometric changes in liver.

Methods Sixty-four (64) male rats were assigned to 8 groups including control groups (normal group and taxol (20 mg/kg group), thymoquinone groups $(4.5,9,18 \mathrm{mg} / \mathrm{kg}$ ) and taxol + thymoquinone (TT) treated groups. All experimental groups were treated intraperitoneally daily for 2 weeks. The relative expression level of apoptotic genes and hepatocyte apoptotic index were analyses. Also, nitrite oxide (NO), lipid peroxidation (LP), total antioxidant capacity (TAC), hepatic enzymes and histomorphometric parameters were evaluated.

Results In the taxol control group (TCG) all parameters investigated in this study significantly increase except TAC level, which was decreased in compared to the normal control group (NCG) $(p<0.01)$. Additionally, all evaluated parameters were reduced in thymoquinone and TT groups, except TAC level (which was increased) as compared to the TCG $(p<0.01)$

Conclusion Our results discovered that thymoquinone successfully moderate liver injury induced by taxol through the activation of antioxidant pathways, reduce the apoptogenic and the regeneration of histopathological alterations.

Keywords Thymoquinone, Apoptogenic, Antioxidant, Liver, Taxol
\end{abstract}

\section{Introduction}

Anticancer medications increase the longevity of many cancer patients but possibly will have adverse effects on other body tissues. ${ }^{1}$ Taxol (Paclitaxel) is a chemotherapy drug applicable to treat a number types of malignance and mainly metabolized in the liver by p450 cytochrome and is emitted through bile. ${ }^{2}$ Liver is a vital body structure that shows an essential role in detoxification of toxic agents, and chemical drugs as the initially line of body defense. ${ }^{3}$ Firozi-Niyaki et al. demonstrated that taxol administration to female mice significantly raised the hepatic enzymes. ${ }^{4}$ Cure with taxol has also been stated to induce the production of lipid ceramide through lipid membranes and de novo pathway as well as the manufacture of reactive oxygen species (ROS) from the mitochondrial matrix.

Free radicals are active molecules or atoms that, owing to their atomic layer, have a strong desire to combine with other surrounding molecules such as proteins, cell membrane lipids, DNA, lipoproteins, and RNA, can cause tissue damage and diseases such as cancer, hepatic disorders, and cardiovascular if their combining activity is not inhibited. ${ }^{6}$ One of the most important destructive effects of free radicals is lipid peroxidation (LP), which causes cell membrane injury. ${ }^{7}$ These free radicals can induce the production of LP and cellular damages, particularly in hepatic cells by alkylating the protein groups and other cellular macromolecules and attacking unsaturated fatty acids. ${ }^{8}$ Oxidative stress plays a vital role in the hepatic tissue impairment induced by toxins and drugs. ${ }^{9}$ Karaduman et al. found that taxol induced hepatic tissue necrosis and damage, caused fibrosis, and increased sinusoidal space and inflammation in the hepatic tissue of rats. ${ }^{10}$

Various herbs with antioxidant properties apply to protective effects against chemoprotective drugs. One of these herbs is Nigella sativa (NS), which has a therapeutic and religious history. ${ }^{11}$ NS with white flowers that turn black in contact with air, is native to Asia and East Europe belongs to the Ranunculaceae family. ${ }^{12}$ Thymoquinone is the chief compound of the aqueous extract of NS, constituting about $72.94 \%$ of the weight of its oil. ${ }^{13}$ This herb has been reported to have frequent pharmacological properties such as attenuation of glucose, lipid, and hypertension, protection of kidney, and hepatic tissues, and antimicrobial effects owing to its antioxidant, anti-inflammatory effects. ${ }^{14}$ Daba et al. described the antioxidant effects of NS against liver toxicity induced by cisplatin. ${ }^{15}$ Additionally, administration of NS oil for lead-induced hepatotoxicity has been informed to prevent pathologica disorders in the hepatic tissue. ${ }^{16}$

Given the antioxidant properties of thymoquinone, it seems that this substantial can shield the liver against taxol-induced oxidative impairment. A review of the literature similarly reveals no study has investigated the protective effects of thymoquinone against destructive effects of taxol through reduce apoptogenic and oxidative stress index and improve histomorphometric change on liver tissue in male rats. Hence, the present study was conducted to evaluate the protective effects of thymoquinone against taxol on some hepatic parameters.

\section{Materials and Methods}

\section{Animals}

For experimental treatments, 64 male rats (Wistar, 20-250 g, 8 weeks) were prepared from a specialized center of laboratory animals (Pasteur, Tehran, Iran). Standard animal keeping conditions were applied carefully including: $12 \mathrm{~h}$ light/12 $\mathrm{h}$ dark phase, $22 \pm 2^{\circ} \mathrm{C}$ availability of water and food. The 
experimental medications and treatments conformed to the ethical and humane principles of research. It was accepted by the Ethics Committee of the related institute Committee on the Use and Care of Animals, IR.KUMS.REC.1397.618.

\section{Experimental Protocol, Dissection and Sampling}

The animals were randomly divided into 8 groups $(n=8)$, including: 1: First group, the NCG, which received normal saline (intraperitoneally injection) equivalent to the amount of experimental groups. Second group, the TCG, in this group, the rats was given taxol at a dose of $20 \mathrm{mg} / \mathrm{kg}$ (single dose) intraperitoneally injected for 2 weeks. The mice in the both TCG and NCG groups were not given any treatment after taxol and normal saline injection until sacrifice. Third to fifth groups, the thymoquinone administration groups, in these groups, each animal, respectively, received $4.5,9$, and $18 \mathrm{mg} / \mathrm{kg}$ of thymoquinone intraperitoneally for 2 weeks. Sixth to eighth groups, TT administration groups, in this group, each animal received single dose $(20 \mathrm{mg} / \mathrm{kg})$ of taxol intraperitoneally in order to induce hepatic damage, then (after taxol injection) they respectively received $4.5,9$, and $18 \mathrm{mg} / \mathrm{kg}$ of thymoquinone intraperitoneally for 2 weeks. At the end of the treatment period, all rats were deeply anesthetized by intraperitoneally injection of Ketamine $\mathrm{HCl}(100 \mathrm{mg} / \mathrm{kg})$ and Xylazine $(10 \mathrm{mg} /$ $\mathrm{kg}$ ). The sampling included blood from the hearts (at least $1 \mathrm{ml}$ per animal) for evaluating the antioxidant levels. The animals were then sacrificed and the liver was removed. ${ }^{6,10}$

\section{Evaluation of Functional-Related Enzymes}

The liver homogenate was centrifuged twice $(12,000 \mathrm{rpm}, 10$ $\min )$. Then, the supernatant was parted for measurement of hepatic enzymes, including aminotransferase (AST), alanine aminotransferase (ALT), and alkaline phosphatase (ALP). The ALT and AST were tested based on Reitman and Frankel biochemical methods. The ALP protocol was also determined according to the technique which was set out in the practical research laboratory.

\section{Histomorphometric Analyses}

To assess histomorphometric alterations, a section of the liver tissue was fixed in $10 \%$ formalin. The tissues were then fixed in paraffin, and the thin sections $(4 \mu \mathrm{m})$ were prepared using a microtome (Leica RM 2125, Germany). The slices were then stained with hematoxylin and eosin. Thereafter, some morphological assessments including full cellular area, hepatocyte outline, maximum and minimum axis, mean axis, and $\mathrm{CVH}$ were determined by light microscope at $40 \times$ magnification. At least 50 cells from the separate region were measured to eliminate the probable measurement bias. All procedures were applied with an investigation microscope coupled with a DP12 Camera (3.34-million pixel resolution) and using the Olysia Bio-software (Olympus Optical Co. LTD, Tokyo, Japan). ${ }^{6}$

\section{Measurement of LP Levels}

The level of molecular reaction among thiobarbituric acid and malondialdehyde (MDA) following colorimetry process was considered as the measurement of lipid peroxidation levels. The frozen sample of the pancreas tissue was used. First, the tissue was washed with the phosphate-buffered saline at $\mathrm{pH}$ of 7. Then, an ultrasonic homogenizer in a cold phosphate buffer containing ethylene diamine tetra-acetic acid was hired to apply tissue homogenization. $20 \mu \mathrm{l}$ of supernatant was mixed within the test tubes. The test tube contained $4 \mu \mathrm{l}$ of butylated hydroxytoluene, $20 \mu \mathrm{l}$ of phosphoric acid (1M), and $20 \mu \mathrm{l}$ of TBA solution. The test tube was incubated for $60 \mathrm{~min}$ at $70^{\circ} \mathrm{C}$, then it was centrifuged ( $10000 \mathrm{rpm}, 4 \mathrm{~min}$ ). $80 \mu \mathrm{l}$ of the supernatant was poured into the spectrophotometer tubes. The produced dye in the commercial kit was read at $532 \mathrm{~nm}$, and in conclusion, the MDA level was stated in $\mathrm{nmol} / \mathrm{mg}$ protein.?

\section{Estimation of Liver TAC}

Total antioxidant capacity (TAC) of the serum was analyzed by the FRAP technique based on the ability of the plasma to reinstate the ferric. A blue color was made when the complex of FeIII-TPTZ in acidic $\mathrm{pH}$ payback to FeII and the absorption at the extreme wavelength of $500 \mathrm{~nm}$. The element defining the speed of the FeII-TPTZ and blue stain was merely the vitalizing power of the sample. TAC values are strategized via the standard curve. ${ }^{3}$

\section{Assessment of NO}

The Griess method based on colorimetry approaches was employed to measure the NO levels. $500 \mu \mathrm{l}$ of serum was deproteinized with zinc sulfate $(10 \mathrm{mg})$. After centrifugation at $3000 \mathrm{rpm}$ for $10 \mathrm{~min}$, the equal amounts of Griess reagent ( $1 \%$ sulfanilamide, $0.1 \%$ naphtylethylenediamide in $2.5 \%$ phosphoric acid) were also added to the supernatant in 96-well ELISA plates and incubated for $10 \mathrm{~min}$ at $37^{\circ} \mathrm{C}$. The absorbance was stately at $450 \mathrm{~nm}$ with the use of a microplate reader. Nitrite concentrations were considered by a sodium nitrite standard curve. ${ }^{6}$

\section{Apoptosis Assay}

The TUNEL test was performed according to the manufacture's procedure (Roche, Germany). Paraffin-embedded blocks were prepared using an automatic tissue processor. $5 \mu \mathrm{m}$ histological slices were cut through a microtome (Leica, Germany), and five slices per rat were selected. The tissues were subjected to deparaffinization. After routine deparaffinization and blocking, the slices were exposed to TdT with DIG. DIG labeling and counterstaining were then carried out. To quantitate the rate of apoptosis, the number of positive cells within the liver was calculated.

\section{Real-Time Quantitative PCR}

The real-time PCR evaluated the liver genes expression of p53 and Bax. The tissue was frozen in nitrogen and then stored in at $-70{ }^{\circ} \mathrm{C}$ freezer. RNA was removed using RNeasy mini kit (Qiagen, Tehran, Iran) based on the manufacturer's instructions. DNA was treated via DNase set kit (Qiagen, Tehran, Iran). The RNA was hired in order to cDNA production through cDNA Synthesis Kit. The expression level of the related genes was measured through glyceraldehyde-3-phosphate dehydrogenase primer as endogenous control by SYBR Green (Fermentas, Tehran, Iran) through comparative CT method. The primer nucleotide sequences are listed in Table $1 .{ }^{16}$

\section{Statistical Analyses}

One way analysis of variance (one-way ANOVA) and Tukey post hoc test were used to statistical analysis and differences among the groups, respectively. Statistical software package of SPSS (Chicago, IL) was used for data analysis. The final outcomes were expressed as mean \pm standard error, and $p<0.05$ was considered significant. 


\begin{tabular}{lc}
\hline $\begin{array}{l}\text { Table 1. Primers used in real-time } \mathbf{P C R} \\
\text { Primer sequences }\end{array}$ & \multicolumn{1}{c}{ Primer ID } \\
\hline GAPDH & F :50- AAGCTCATTTCCTGGTATG-30 \\
& R: 50- CTGCCACAAGAACTAGAGA-30 \\
p53 & F:50-AGAGACCGCCGTACAGAAGA-30 \\
& R:50-GCATGGGCATCCTTTAACTC-30 \\
Bax & F: $50-C C G G C G A A T T G G A G A T G A A C T-30$ \\
& R: 50-CCAGCCCATGATGGTTCTGAT-30 \\
\hline
\end{tabular}

\section{Results \\ Effect of Taxol and Thymoquinone on Liver Functional-Related Enzymes}

Taxol led to a significantly increased in enzymes in TCG comparison with the NCG $(p<0.01)$. The mean enzymes level concentration was not significant in thymoquinone groups compared to the NCG $(p>0.05)$. Also, in thymoquinone and TT groups significantly decreased in the mean of enzymes were detected in comparison with the TCG $(p<$ 0.01) (Table 2).

\section{Morphometric Measurements}

The mean diameter of hepatocytes and central hepatic vein $(\mathrm{CHV})$ in experimental groups showed a significant difference between the NCG and TCG groups $(p<0.01)$. The mean diameter of hepatocytes and CHV was not significant in thymoquinone groups compared to the NCG $(p>0.05)$. Further, in thymoquinone and TT groups the mean diameter of hepatocytes and CHV significantly reduced in comparison with TCG $(p<0.01)$ (Fig. 1).

\section{Histopathological Changes}

Histological analysis showed normal liver structure in the NCG, TT, and thymoquinone treatment groups. After treatment with taxol in TCG, the hepatic tissue showed evident changes and injury. These anomalies included increased apoptotic cells, increased irregularities, hyperemia, sinusoidal dilatatio, $n$ and enlargement of CHV. Treatment with TT at all doses reduced the liver damage caused by taxol harmfulness (Fig. 2).

\section{Apoptotic Index}

The apoptotic index (AI) was significantly higher in TCG compared to the NCG $(p<0.01)$. No significant differences were similarly found in the AI in all thymoquinone groups as compared to the NCG $(p>0.05)$. Furthermore, whole several doses of thymoquinone in thymoquinone and TT groups

\begin{tabular}{|c|c|c|c|c|c|c|c|c|}
\hline \multirow{2}{*}{$\begin{array}{l}\text { Enzymes } \\
\text { (ng/ml) }\end{array}$} & \multirow{2}{*}{$\begin{array}{l}\text { Normal } \\
\text { control }\end{array}$} & \multirow{2}{*}{$\begin{array}{l}\text { Taxol } \\
\text { control }\end{array}$} & \multicolumn{3}{|c|}{ Thymoquinone (mg/kg) } & \multicolumn{3}{|c|}{ Thymoquinone + Taxol (mg/kg) } \\
\hline & & & 4.5 & 9 & 18 & 4.5 & 9 & 18 \\
\hline AST & $71.25 \pm 4.20$ & $132.21 \pm 8.25^{*}$ & $75.85 \pm 5.47 \dagger$ & $71.32 \pm 4.36 \dagger$ & $69.11 \pm 6.71 \dagger$ & $99.01 \pm 7.2 \neq$ & $85.84 \pm 8.12 \neq$ & $84.65 \pm 5.3 \neq$ \\
\hline ALT & $29.28 \pm 3.25$ & $63.98 \pm 5.61^{*}$ & $27.45 \pm 3.14 \dagger$ & $30.47 \pm 4.32 \dagger$ & $32.11 \pm 3.82 \dagger$ & $45.01 \pm 2.1 \neq$ & $37.2 \pm 3.47 \ddagger$ & $35.54 \pm 3.2 \neq$ \\
\hline ALP & $3.02 \pm 0.20$ & $7.97 \pm 1.24^{*}$ & $2.63 \pm 0.52 \dagger$ & $3.04 \pm 0.41 \dagger$ & $3.11 \pm 0.21 \dagger$ & $5.54 \pm 0.83 \neq$ & $4.02 \pm 0.97 \neq$ & $4.01 \pm 0.82 \ddagger$ \\
\hline
\end{tabular}

Data were presented as mean \pm standard deviation. ALP: Alkaline phosphatase, ALT: Alanine aminotransferase, AST: Aspartate aminotransferase. ${ }^{*} p<0.01$ compared to the normal control group. $\uparrow p<0.01$ compared to taxol control group. $\neq p<0.01$ compared to the taxol control group.

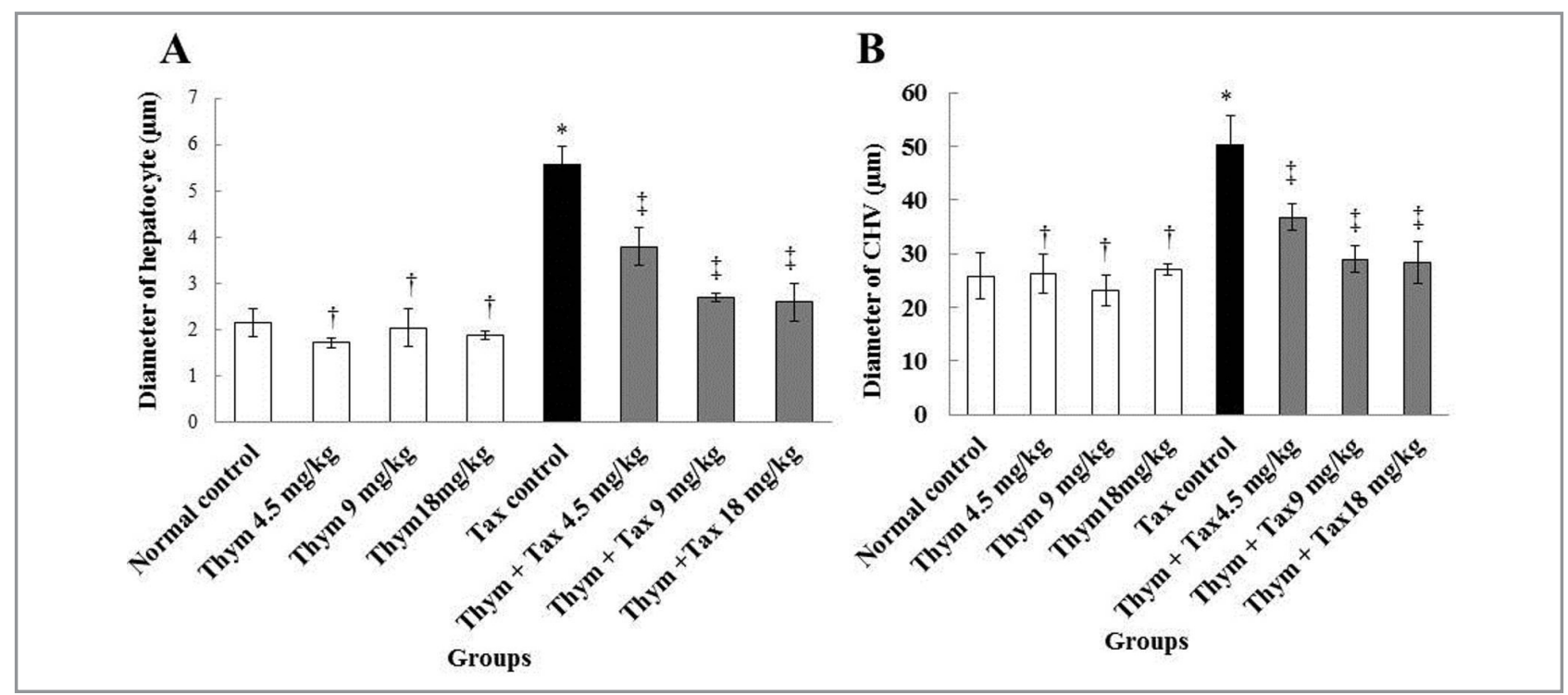

Fig. 1 Effect of taxol and thymoquinone on the hepatocyte diameter (A) and diameter of CHV (B) diameters. *Significant difference to the NCG $(p<0.01)$. HSignificant difference to the TCG $(p<0.01)$. \#Significant difference to the TCG $(p<0.01)$. CHV: Central Hepatic Vein; Thym: Thymoquinone; Tax: Taxol, TCG: Taxol control group. NCG: Normal control group. 


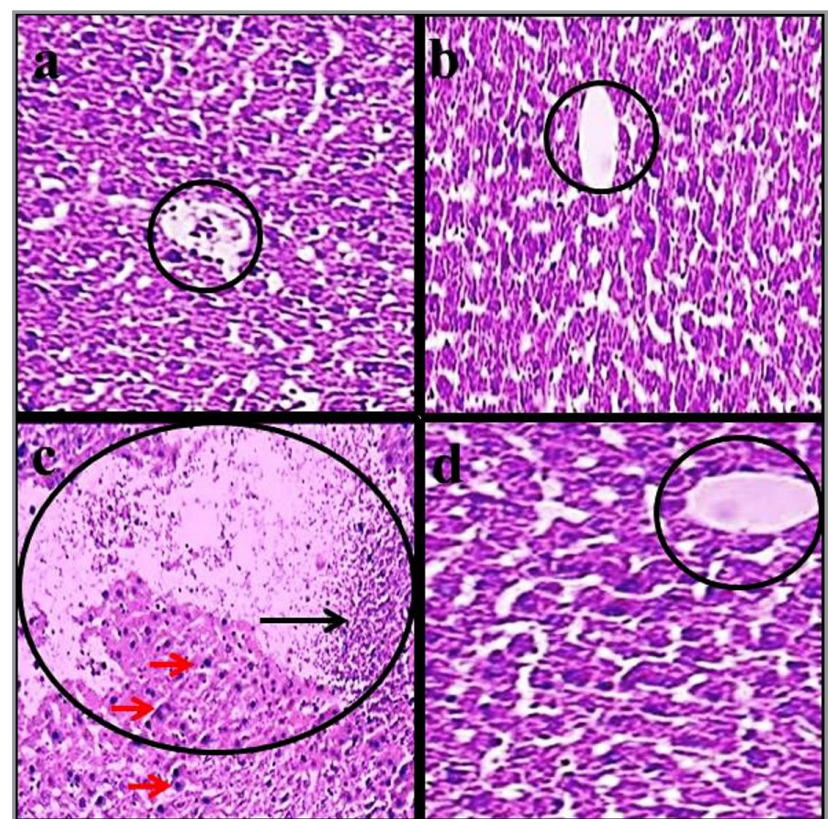

Fig. 2 Microscopic images of liver tissue (Five-micron thick sections, H\&E staining, magnification $\times 100)$. NCG (a), Thymoquinone (18 mg/kg) group (b) and TT group (d): normal tissue structure. TCG $(20 \mathrm{mg} / \mathrm{kg})$ (c): abnormal tissue structure. Apoptotic cells (red arrows), central hepatic vein (circles) and hyperemia (block arrow). TCG: Taxol control group. NCG: Normal control group.
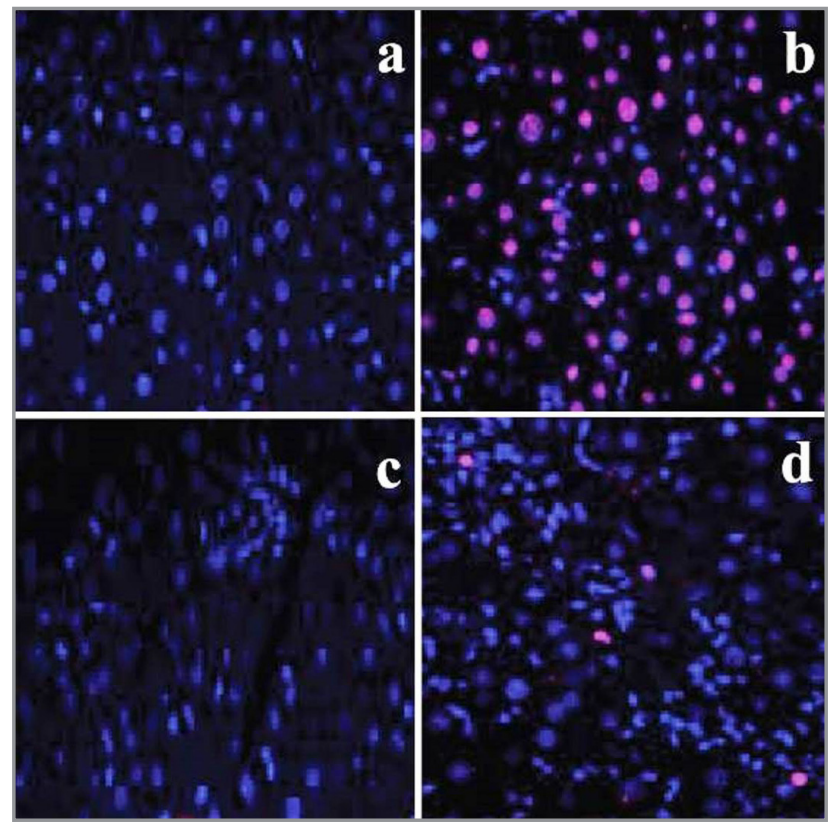

Fig. 3 Apoptosis induction in the hepatocytes following thymoquinone and taxol treatments (400x magnifications, TUNEL staining). NCG (a), Thymoquinone group (18 mg/kg)(b), TCG (20 mg/kg) (c) and TT group (d). shiny red nuclei refers to apoptotic cells. TCG: Taxol control group. NCG: Normal control group.

represented a significant decline in the $\mathrm{AI}$ as compared to the TCG $(p<0.01)$ (Figs. 3 and 4$)$.

\section{Apoptotic Gene Expression Levels}

Upregulated changes of p53 and Bax genes in the TCG compared to the NCG were significantly detected $(p<0.01)$. Also, a significant downregulation of these genes similarly was

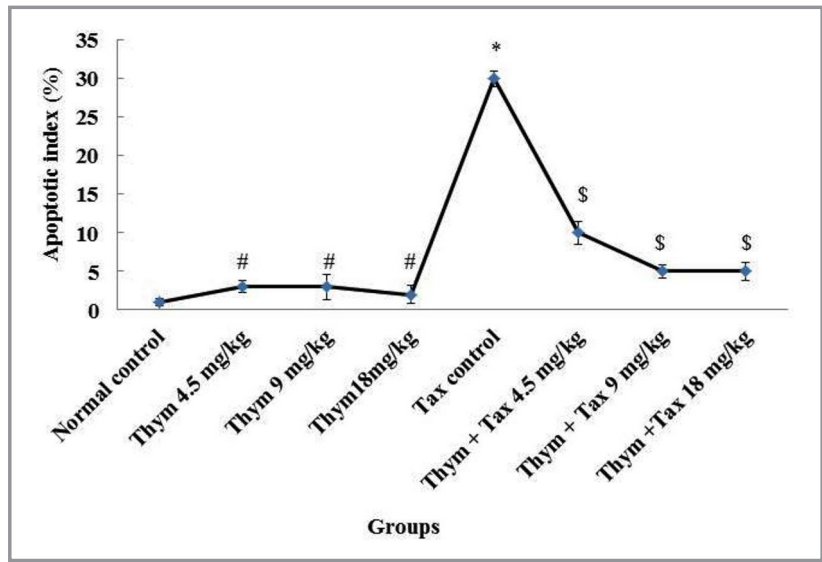

Fig. 4 Apoptotic index in the hepatocytes subsequent thymoquinone and taxol aminestration.

*Significant difference to the NCG $(p<0.01)$. \# Significant difference to the TCG $(p<0.01)$. \$ Significant difference to the TCG $(p<0.01)$. Thym: Thymoquinone; Tax: Taxol. Taxol control group. NCG: Normal control group.

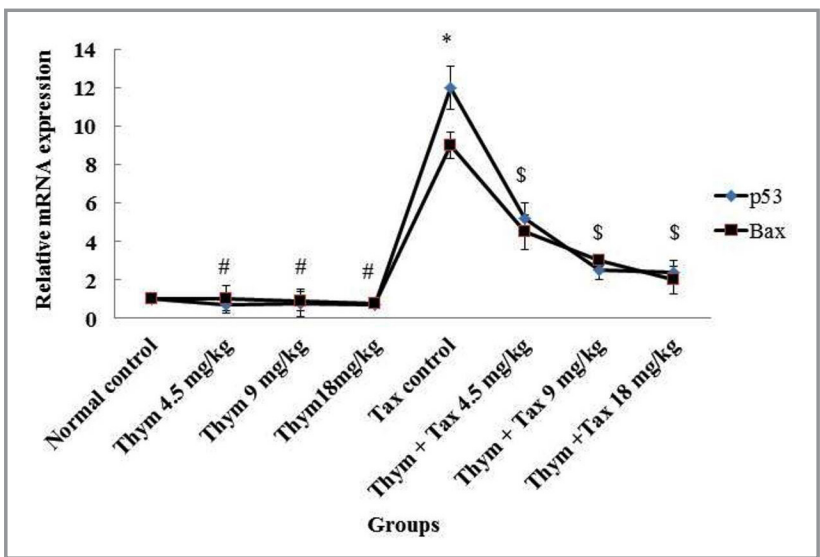

Fig. 5 Relative gene expression following thymoquinone and taxol administration. * Statistically significant $(p<0.01)$ between NCG and TCG \$ Statistically significant $(p<0.01)$ between TCG and TT groups. \# Significant modifications in Thymoquinone groups as compared to the TCG $(p<0.01)$. Thym: Thymoquinone; Tax: Taxol. TCG: Taxol control group. NCG: Normal control group

distinguished in all doses of thymoquinone and TT groups as compared to the TCG group (Fig. 5).

\section{Levels of TAC, LP, and NO}

In the TCG, the TAC levels were lower than the NCG significantly $(p<0.01)$. Also, in whole groups of thymoquinone and TT, the TAC levels were considerably elevated as compared to the TCG $(p<0.01)$ due to the thymoquinone administration. Taxol, due to its detrimental effects, significantly increased the NO and LP levels in TCG in comparison with the NCG $(p<$ $0.01)$. It is also found that all doses of thymoquinone can significantly reduce the mean levels of NO serum and LP in the thymoquinone and TT groups as compared to the TCG $(p<$ 0.01) (Table 3).

\section{Discussion}

Chemotherapy, the chief factor complicated in oxidative stress, can disrupt the construction and performance of hepatic tissue, one of the vital body structures and the primarily protection barrier that shows an essential role in detoxification 


\begin{tabular}{|c|c|c|c|}
\hline Groups & $\mathrm{NO}(\mathrm{mmol} / \mathrm{ml})$ & $\mathrm{TAC}(\mathrm{mmol} / \mathrm{ml})$ & $\mathrm{LP}(\mathrm{nmol} / \mathrm{mg})$ \\
\hline Normal control & $42.25 \pm 4.36$ & $99.74 \pm 7.24$ & $0.92 \pm 0.06$ \\
\hline Taxol control & $198.69 \pm 8.25^{*}$ & $18.22 \pm 3.12^{*}$ & $0.42 \pm 0.01^{*}$ \\
\hline $\begin{array}{l}\text { Thymoquinone } \\
4.5 \mathrm{mg} / \mathrm{kg}\end{array}$ & $44.02 \pm 3.52 \dagger$ & $98.46 \pm 8.06 \dagger$ & $0.97 \pm 0.03 \dagger$ \\
\hline $\begin{array}{l}\text { Thymoquinone } \\
9 \mathrm{mg} / \mathrm{kg}\end{array}$ & $43.65 \pm 6.98 \dagger$ & $95.97 \pm 5.58 \dagger$ & $0.92 \pm 0.04 \dagger$ \\
\hline $\begin{array}{l}\text { Thymoquinone } \\
18 \mathrm{mg} / \mathrm{kg}\end{array}$ & $41.82 \pm 6.36+$ & $99.11 \pm 8.82 \dagger$ & $0.96 \pm 0.01 \dagger$ \\
\hline $\begin{array}{l}\text { Thymoquinone + } \\
\text { Taxol } 4.5 \mathrm{mg} / \mathrm{kg}\end{array}$ & $93.16 \pm 5.149$ & $42.71 \pm 5.219$ & $0.61 \pm 0.029$ \\
\hline $\begin{array}{l}\text { Thymoquinone } \\
+ \text { Taxol } 9 \text { mg/kg }\end{array}$ & $72.71 \pm 6.749$ & $49.34 \pm 3.469$ & $0.59 \pm 0.019$ \\
\hline $\begin{array}{l}\text { Thymoquinone } \\
+ \text { Taxol } 18 \mathrm{mg} / \mathrm{kg}\end{array}$ & $73.39 \pm 3.319$ & $51.96 \pm 3.999$ & $0.57 \pm 0.059$ \\
\hline
\end{tabular}

Data are presented as mean \pm SEM. ${ }^{*} p<0.01$ compared to the control group. $\uparrow p<0.01$ compared to taxol control group. $\uparrow p<0.01$ compared to the taxol control group. NO: Nitrite oxide, TAC: Total antioxidant capacity, LP: Lipid peroxidation.

of chemical medications. ${ }^{17}$ Consequently, concurrent consumption of potential antioxidant plants and chemotherapy medications has drastically improved in order to safeguard the cells in contrast to the damaging effects of free radicals. ${ }^{20}$ The outcomes of the present investigation recommended that taxol administration had adversative effects on hepatic histology and function, increase apoptotic cells and gene expression, and antioxidant imbalance as well, and increase in NO level. On the other hand, thymoquinone as an herbal, relieve the diverse effects of taxol administration, perceptibly in liver parameter.

The current study outcomes moreover revealed that thymoquinone is able to condense LP and increase TAC of hepatic tissue, consequently it is dropping oxidative stress. Consistent with these outcomes, some of papers has offered antioxidant properties of thymoquinone..$^{6,14,15}$ Thymoquinone appears to inhibit the LP induced by TBH in the liver tissue. ${ }^{6}$ Additional, thymoquinone is a lipophilic molecule that is capable to prevent LP via Fenton reaction. ${ }^{19}$ Gani et al. indicated that extract of NS diminished hepatic enzymes and LP, which is in line with the outcomes of the existing study. ${ }^{20}$ Accordingly, it appears that thymoquinone with its antioxidant properties could condense LP and increase TAC in the treatment groups via inhibiting the construction of ROS. Present study similarly showed the recovery effect of thymoquinone on liver tissue as well as lessening the oxidative stress by displaying falling of LP. The injuriousness of taxol administration can lead to blood and biochemical modifications, oxidative stress, and LP. Hence, mechanism for toxicity of taxol drug combinations is oxidative stress. ${ }^{21}$

The findings discovered that, compared to the NCG, the CHV and diameters of hepatocytes in the TCG has significantly decreased. In addition, there was a significant reduction in the diameter of hepatocytes and size of the CHV in thymoquinone and TT groups were detected compared to the TCG group. It appears that taxol has hepatotoxic effects, due to increased glutathione, and causes the loss of liver cytoplasmic cells. ${ }^{10}$ Changing the size of CHV and liver cells can rise the metabolic action of hepatocytes to defecate the toxin from the body throughout detoxification course. ${ }^{3}$ The taxol metabolism made free radicals then it causes LP, DNA, and membrane proteins reaction and subsequently cell impairment through several ways. ${ }^{7}$ Thymoquinone, as the antioxidant herb, has an inhibitory effect on cytochrome P450, inhibits additional taxol metabolism and diminish the construction of free radicals. $^{6}$ The outcomes of the existing study agree with the consequences of the study of Salahshoor et al., in which they displayed that Genistein administration as a herb antioxidant improves liver damage, resulted in the decreasing diameter of hepatocytes. $^{3}$

Additional imperative finding was that some modifications in the liver tissue were perceived in the TCG that were in the form of the plethoric state of the sinuses, Kupffer cells accretion around the CHV and growth in the apoptotic cells, as well as the CHV diameter enlargement. It appears that the attack of free radicals to hepatocyte causes apoptosis in parenchymal cells. ${ }^{7}$ Kupffer cells can prompt inflammatory reactions in the hepatic tissue, which leads to tissue impairment. ${ }^{22}$ Apparently, Kupffer cells are triggered in reply to tissue damage and release mediators, such as the TNF and NO. ${ }^{6}$ It may appear that the Kupffer cells secretion of toxic mediators in the zones, that have not experienced necrosis yet, are complicated in causing hepatic toxicity and necrosis. ${ }^{25}$ Besides, free radicals' construction and following oxidative stress can be one of the most dangerous and important causes of the hepatocyte death. ${ }^{3}$ The current outcomes support the concepts of Cresteil et al. who display that the liver harm and apoptosis in liver cells can be caused by taxol. ${ }^{24}$ Thymoquinone appears to carry out a protective result contrary to fibrogenesis on the liver tissue through polyphenol capacity and by stopping the stellate cells activity and stating the cell cycle protein. ${ }^{25}$ Stellate cells show a central part in the enhancement of hepatic fibrosis and oxidative stress. ${ }^{6}$ It seems that thymoquinone has the ability to inhibit macrophage. Thymoquinone can exert its anti-inflammatory properties on NF-K $\beta$ by reducing $\mathrm{H} 2 \mathrm{O} 2$ production. ${ }^{26}$ Kanter et al. shown that thymoquinone prevents the induction of ethanol's undesirable properties through the inhibition of lipid's induction, which is matched with the outcomes of the present study. ${ }^{27}$

The consequences of this study show that there is a significant alteration between TAC and hepatic enzyme levels in the TCG and the NCG. Correspondingly, there's a negative association, between TAC in the TCG and enzyme levels in the thymoquinone and TT groups. The progression of the liver enzymes in serum indicates a hepatic damage in the present study. Besides, the results of Nili et al. confirmed the consequences of the present study in that thymoquinone could decline enzymes serum levels. ${ }^{28}$ Liver enzymes can be released into the serum due to the prevalence of cell membrane impairment. ${ }^{6}$ It may be possible that taxol induce destruction to the hepatocyte membrane through the inhibition of respiratory sequence. ${ }^{29}$ The consequences are in agreement with Harris et al. conclusions, which show that the taxol administration in rats for 1 week induces the growth of hepatic enzymes and equally condense the TAC. ${ }^{30}$ Thymoquinone seems to stabilize hepatocyte membranes and stops outflow of enzymes by stopping LP. ${ }^{15}$ Thymoquinone can apply its antioxidant properties through reducing LP and inducing antioxidant enzymes. ${ }^{6}$ The current outcomes are consistent with the results of Pari et al. who suggested that 
administration of thymoquinone condenses liver enzymes in diabetic rats and inhibits damages to liver cells. ${ }^{31}$

In this study, the thymoquinone also showed decreased effects of Bax and p53 (apoptotic genes) gene expression and apoptotic hepatocyte index. P53 makes the mitochondrial membrane permeable to the influx of cytochrome-c into the intracellular matrix. Accordingly, p53 adjusts the function of apoptotic elements like Caspase and Bax. ${ }^{32}$ As cell death is seen in hepatocytes, it is stated that the taxol has upregulation effects on apoptotic factors. ${ }^{33}$ Also, thymoquinone directly translocate within the intranuclear space to induce downregulation of related genes. ${ }^{34}$ De et al. also found that the apoptotic genes are expressed significantly after taxol administration. ${ }^{35}$ In the current study, thymoquinone reduced apoptotic cell index and apoptotic gene expression to prevent cell death. Based on the obtained results, it can be indicated that thymoquinone owns positive antioxidant effects on molecular function and histological construction of liver cells.

The consequences of this study showed a significant rise in the amount of NO in blood in the TCG compared to the NCG. Besides, there was a significant reduction in the TT group in NO level compared to TCG. It seems that oxidative stress increases the production of NO synthase, and therefore indications to rise in nitrite production and fall in cell endurance. ${ }^{3}$ Mitochondria dysfunction, due to the extraordinary consumption of $\mathrm{O}_{2}$, may possibly increase the creation of free radicals in most body tissues, including NO radicals, and due to the nitrosative and oxidative stress and damage to the tissues, particularly the hepatic tissue. $^{7}$ The results are in contract with of Jalili et al. conclusions, which displayed that thymoquinone can condense NO in morphine-induced damage to the hepatic tissue. ${ }^{6}$ The consequences are in concurrence with new studies representative that taxol, as one of the chemotherapy medications, is seemingly able to impairment hepatocytes, increase apoptogenic, liver enzymes, NO, LP, and reduce TAC, by inducing oxidative stress. In contrast, thymoquinone, a strong antioxidant herb, can condense the destructive effects of this drug. Consequently, consuming thymoquinone can be a good approach to lessen free radicals and inhibit injuries to the hepatic tissue of the patients who are exposed to taxol drug for chemotherapy.

\section{Conclusion}

The present study showed that hepatoprotective properties of the thymoquinone in contrary to Taxol-induced liver destruction in rats. The outcomes of this study revealed that taxol administration would outbreak dangerous impress from the point of both hepatic histology and function. It was found that thymoquinone reduces ROS, cell apoptosis, expression of p53, and Bax gens, activating antioxidant agents, and detoxifying enzymes. Therefore, thymoquinone might be considered to recover the functional and histological of the hepatocyte exposed to taxol drug. This protecting conclusion can be reconciled through the antioxidant properties of thymoquinone. Thymoquinone can be considered as a substitute beneficial agent against oxidative damages induced by toxic drug. But, extra studies are necessary to define its exact mechanism of action.

\section{Acknowledgments}

The authors thank Kermanshah University of Medical Sciences for its support.

\section{Conflict of interest}

The authors declare no conflict of interest.

\section{References}

1. Cao X, Hou J, An Q, Assaraf YG, Wang X. Towards the overcoming of anticancer drug resistance mediated by p53 mutations. Drug Resist Updat. 2020;49:100671.

2. Nazhand A, Durazzo A, Lucarini M, Mobilia MA, Omri B, Santini A. Rewiring cellular metabolism for heterologous biosynthesis of Taxol. Nat Prod Res. 2020:34(1):110-21.

3. Salahshoor MR, Roshankhah S, Hosseni P, Jalili C. Genistein improves liver damage in male mice exposed to morphine. Chin Med J 2018;131:1598_ 604.

4. Firozi-Niyaki M, Barari AR, Abbassi-Daloii A. The effect of endurance training and taxol consumption on cyclooxygenase-2 and prostaglandin E2 levels in the liver tissue of mice with cervical cancer. J Kashan Univ Med Sci. 2018:22:517-24.

5. Karaduman D, Eren B, Keles ON. The protective effect of beta-1, 3-D-glucan on taxol-induced hepatotoxicity: A histopathological and stereological study. Drug Chem Toxicol. 2010;33:8-16

6. Salahshoor MR, Vahabi A, Roshankhah Sh, Shabanizadeh Darehdori A, Jalili C. The effects of thymoquinone against morphine-induced damages on male mice liver. Int J Prev Med. 2018;9:8.

7. Salahshoor MR, Abdolmaleki A, Jalili C, Roshankhah S, Ziapour A. Determination of histopathological and biomedical parameters in protective effects of Petroselinum crispum on hepatotoxicity induced by dichlorvos in male Wistar rats. Comp Clin Path. 2020;2:1-9.

8. Ali BM, Velavan B, Sudhandiran G, Sridevi J, Nasar AS. Radical dendrimers: Synthesis, anti-tumor activity and enhanced cytoprotective performance of TEMPO free radical functionalized polyurethane dendrimers. Eur Polym J. 2020;122:109354.

9. Jayakumar T, Huang HC, Hsia CW, Fong TH, Khamrang T, Velusamy M, et al. Ruthenium derivatives attenuate LPS-induced inflammatory responses and liver injury via suppressing NF-KB signaling and free radical production. Bioorg Chem. 2020;96:103639.

10. Karaduman D, Eren B, Keles ON. The protective effect of beta-1, 3-D-glucan on taxol-induced hepatotoxicity: A histopathological and stereological study. Drug Chem Toxicol. 2010;33:8-16.

11. Mazaheri Y, Torbati M, Azadmard-Damirchi S, Savage GP. Effect of roasting and microwave pre-treatments of Nigella sativa L. seeds on lipase activity and the quality of the oil. Food Chem. 2019;274:480-6.

12. Mukhtar H, Qureshi AS, Anwar F, Mumtaz MW, Marcu M. Nigella sativa L. seed and seed oil: potential sources of high-value components for development of functional foods and nutraceuticals/pharmaceuticals. Essent Oil Res. 2019;14:1-3.

13. Kausar H, Mujeeb M, Ahad A, Moolakkadath T, Aqil M, Ahmad A, et al. Optimization of ethosomes for topical Thymoquinone delivery for the treatment of skin acne. J Drug Deliv Sci Technol. 2019;49:177-87.

14. Geng D, Zhang S, Lan J. Analysis on chemical components of volatile oil and determination of Thymoquinone from seed of Nigella glandulifera. Zhongguo Zhong Yao Za Zhi. 2009:34:2887-90.

15. Daba MH. Hepatoprotective activity of Thymoquinone in isolated rat hepatocytes. Toxicol Lett. 1998;95:23-9.

16. Esfandiari E, Roshankhah S, Mardani M, Hashemibeni B, Naghsh E, Kazemi $M$, et al. The effect of high frequency electric field on enhancement of chondrogenesis in human adipose-derived stem cells. Iran J Basic Med Sci. 2014; 17:571-76.

17. Bridgewater JA, Pugh SA, Maishman T, Eminton Z, Mellor J, Whitehead A, et al. Systemic chemotherapy with or without cetuximab in patients with resectable colorectal liver metastasis (New EPOC): Long-term results of a multicentre, randomised, controlled, phase 3 trial. Lancet Oncol. 2020;21:398-411.

18. Zhang Y, Wu Z, Yu H, Wang H, Liu G, Wang S, et al. Chinese herbal medicine Wenxia Changfu formula reverses cell adhesion-mediated drug resistance via the integrin B1-PI3K-AKT pathway in lung cancer. J Cancer. 2019;10:293-304

19. Dera A, Rajagopalan P. Thymoquinone attenuates phosphorylation of AKT to inhibit kidney cancer cell proliferation. J Food Biochem. 2019;e12793.

20. Gani M. Evalution of hepatoprotective effect of Nigella sativa L. J Pharm Pharm Sci. 2013:4:428-30.

21. Meshkini A, Yazdanparast R. Involvement of oxidative stress in Taxol-induced apoptosis in chronic myelogenous leukemia K562 cells. Exp Toxicol Pathol. 2012;64:357-65. 
22. Raushan HR, Seth PK. Behavioral neurochemical and neuromorphological effects of deltamethrin in adult rats. J Toxicol Environ Health. 2010;48:515-6.

23. Amouoghli Tabrizi B MD. Protective effect of edible turmeric powder on early hepatic injury in diabetic rats. J Kashan Univ Med Sci. 2010;14:190-9.

24. Cresteil T, Monsarrat B, Alvinerie P, Tréluyer JM, Vieira I, Wright M. Taxol metabolism by human liver microsomes: Identification of cytochrome P450 isozymes involved in its biotransformation. Cancer Res. 1994;54:386-92.

25. Bai T, Lian LH, Wu YL, Wan Y, Nan JX. Thymoquinone attenuates liver fibrosis via PI3K and TLR4 signaling pathways in activated hepatic stellate cells. Int J Immunopharmacol. 2013;15:275-81.

26. Nagi MN, Almakki HA, Sayed-Ahmed MM, Al-Bekairi AM. Thymoquinone supplementation reverses acetaminophen-induced oxidative stress, nitric oxide production and energy decline in mice liver. Food Chem Toxicol. 2010;48:2361-5

27. Kumar GN, Walle UK, Walle T. Cytochrome P450 3A-mediated human liver microsomal taxol 6 alpha-hydroxylation. J Pharmacol Exp Ther 1994;268:1160-5.

28. Nili-Ahmadabadi A, Tavakoli F, Hasanzadeh GR, Rahimi HR, Sabzevari O. Protective effect of pretreatment with thymoquinone against Aflatoxin B1 induced liver toxicity in mice. Daru. 2011;19:282.

29. Harris JW, Rahman A, Kim BR, Guengerich FP, Collins JM. Metabolism of taxol by human hepatic microsomes and liver slices: Participation of cytochrome P450 3A4 and an unknown P450 enzyme. Cancer Res. 1994;54:4026-35
30. Harris JW, Rahman A, Kim BR, Guengerich FP, Collins JM. Metabolism of taxol by human hepatic microsomes and liver slices: Participation of cytochrome P450 3A4 and an unknown P450 enzyme. Cancer Res. 1994;54:4026-35.

31. Pari L, Sankaranarayanan C. Beneficial effects of Thymoquinone on hepatic key enzymes in streptozotocin-nicotinamide induced diabetic rats. Life Sci. 2009;85:830-4.

32. Al Humayed S, Al-Hashem F, Haidara MA, El Karib AO, Kamar SS, Amin SN, et al. Resveratrol pretreatment ameliorates p53-Bax axis and augments the survival biomarker B-cell lymphoma 2 modulated by paracetamol overdose in a rat model of acute liver injury. Pharmacol. 2020;105:39-46.

33. Minero VG, De Stefanis D, Costelli P, Baccino FM. and in vivo conditional sensitization of hepatocellular carcinoma cells to TNF-induced apoptosis by Taxol. Cell cycle.2020;14:1090-1102.

34. Chae IG, Song NY, Kim DH, Lee MY, Park JM, Chun KS. Thymoquinone induces apoptosis of human renal carcinoma Caki-1 cells by inhibiting JAK2/ STAT3 through pro-oxidant effect. Food Chem Toxicol. 2020;9:253-259.

35. De A, De A, Sharma R, Suo W, Sharma M. Sensitization of carboplatinumand taxol-resistant high-grade serous ovarian cancer cells carrying p53, BRCA1/2 mutations by Emblica officinalis (Amla) via multiple targets. J Cancer. 2020;11:1927-39.

This work is licensed under a Creative Commons Attribution-NonCommercial 3.0 Unported License which allows users to read, copy, distribute and make derivative works for non-commercial purposes from the material, as long as the author of the original work is cited properly. 